\title{
A adoção de Tecnologias da Informação Móveis e Sem Fio (TIMS) e as competências de profissionais de vendas: dois estudos de caso na indústria farmacêutica de Goiás*
}

\section{Adopting Information Technologies Wireless and Mobile (TIMS) and the skills of sales professionals: two case studies in the pharmaceutical industry of Goiás}

Amarolinda Saccol ${ }^{1}$ Francislene Camarotto ${ }^{2}$
* Recebido em: $29 / 06 / 2012$ Aprovado em: 27/03/2013

1 Doutora em Administração pela FEA - USP, mestre em Administração pela UFRGS e graduada em Administração pela UFSM. Atualmente é professora e pesquisadora da Universidade do Vale do Rio dos Sinos (Unisinos).

2 Mestre em Administração pela Universidade do Vale do Rio dos Sinos (Unisinos), graduação em Administração de Empresas pela Associação Goiana de Ensino Faculdade Anhanguera de Ciências Humanas. Atualmente é Professora e Coordenadora de Estágio Curricular e de TCC no Centro Universitário de Anápolis - UniEVANGELICA no Curso de Administração.

\section{Resumo}

Vivemos hoje uma era de mobilidade da comunicação e da computação sem precedentes. Isso se deve ao surgimento e à difusão das Tecnologias da Informação Móveis e Sem Fio (TIMS), como, por exemplo, laptops, assistentes digitais pessoais (PDAs), telefones inteligentes interconectados por redes sem fios. Essas tecnologias possibilitam a comunicação entre profissionais em ambientes diferentes, apoiando diversos processos de negócio, tais como: vendas, logística, trabalhos técnicos em campo etc., o que configura o fenômeno da mobilidade empresarial (enterprise mobility). Diante das possibilidades da mobilidade, muitas organizações precisam readaptar sua estrutura, seus processos de negócio, seus recursos humanos, suas formas de liderança e sua cultura organizacional para se adequar aos novos tipos de atividades que envolvem a mobilidade dos trabalhadores (BASOLE, 2008). Devido à escassez de estudos científicos e de trabalhos acadêmicos que abordem as decorrências da mobilidade corporativa para as competências individuais dos profissionais da área comercial e, mais especificamente, na indústria farmacêutica no Brasil, tornam-se pertinentes pesquisas que considerem as peculiaridades desse contexto. Tais pesquisas poderão fornecer informações, com embasamento teórico, para os gestores e os profissionais dos departamentos de vendas e de recursos humanos, sobre como proceder nas políticas e nas práticas de gestão de pessoas, ao implementar ou renovar capacidades de mobilidade corporativa nos processos comerciais. Diante disso, este artigo enfoca a indústria farmacêutica goiana, mais especificamente, as organizações do Distrito Agroindustrial de Anápolis (DAIA) e procurou explorar a seguinte questão: Quais são as decorrências da adoção de TIMS para as competências dos profissionais da área comercial na indústria farmacêutica no Estado de Goiás? Este estudo realizou também uma investigação por meio da aplicação do método de estudos de casos múltiplos. Foram pesquisadas duas indústrias farmacêuticas localizadas no DAIA, que serão aqui denominadas "Beta Max" e "Alfa", para preservar suas identidades. Foram utilizadas como técnicas de coleta de dados a entrevista semiestruturada e a análise dos sites das empresas pesquisadas, bem como documentos internos. Como principais resultados, verificou-se que a adoção das TIMS afetou o perfil, os conhecimentos e as habilidades dos profissionais de vendas em ambas as empresas pesquisadas, especialmente o saber ouvir o cliente, a transmissão das infor- 
mações e a especialização do profissional no que tange a ser ele adaptável e receptivo a diferentes circunstâncias que envolvam a negociação. Também houve aumento da realização de atividades de BackOffice pelos profissionais da área comercial, bem como, da autonomia em gerenciar as informações sobre clientes e produtos. Com isso, são demandadas competências de gestão dos profissionais sobre os diversos processos que realizam em seu dia a dia de trabalho. Ampliou-se o nível de complexidade das atribuições e das responsabilidades dos representantes comerciais sem se alterar o seu cargo. Também houve exigência de maior agilidade e menor tempo de resposta às demandas e maior cobrança por resultados

Palavras-chaves: Tecnologias da Informação e Comunicação (TICS), Tecnologias da Informação Móveis e Sem Fio (TIMS), Competências, Profissionais de Vendas, Indústria Farmacêutica.

\section{Abstract}

We live today in an era of unprecedented mobile communication and computing. This is due to the emergence and dissemination of Mobile and Wireless Information Technology (MWIT), e.g., laptops, personal digital assistants (PDAs), smartphones, all connected by wireless networks. These technologies enable communication between professionals in different environments, supporting various business processes such as sales, logistics, technical fieldwork, etc.. Which configures the phenomenon of enterprise mobility. Given the possibilities of mobility, many organizations need to adapt its structure, business processes, human resources, forms of leadership and organizational culture to new types of activities involving the mobility of workers (BASOLE, 2008). Due to the scarcity of scientific studies and academic papers that address the consequences of corporate mobility for individual competencies of salespeople, more specifically, in the pharmaceutical industry in Brazil, a research that considers the peculiarities of this context become relevant. Such research may provide information for managers, sales professionals and human resources professionals. Therefore, this article focuses on the pharmaceutical industry of Goiás, more specifically, organizations at the Agroindustrial District of Annapolis (DAIA) and sought to explore the following question: What are the consequences of adopting MWIT for the competences of sales profes- sionals in the pharmaceutical industry of Goiás? This study conducted an investigation through the application of the method of multiple case studies. We researched two pharmaceutical companies located at DAIA, which will be referred to herein as "Beta Max" and "Alpha", to preserve their identities. We used as data collection techniques semi-structured interviews and analysis of the websites of the companies, as well as internal documents. The main results showed that the adoption of MWIT affect the profile, knowledge and skills of sales professionals in both the companies studied, especially the skills of listening and transmitting information to clients, specialized work, and being adaptable and responsive to different circumstances involving trading. In addition, the BackOffice tasks performed by sales professionals have increased, as well as their autonomy to manage customer information and products. Thus, management skills are demanded of these professionals considering the various processes that they perform in their daily work. The level of complexity of the tasks and the responsibilities of sales representatives increased, without a change on their job description. There is also need for greater flexibility and faster response time to the work demands and greater accountability for sales results.

Keywords: Information and Communication Technologies (ICT), Mobile and Wireless Information Technology (MWIT), Competences, Sales Professionals, Pharmaceutical Industry.

\section{Introdução}

Vivemos hoje em uma era de mobilidade da comunicação e da computação sem precedentes. Isso se deve ao surgimento e difusão das Tecnologias da Informação Móveis e Sem Fio (TIMS), tais como: laptops, Assistentes Digitais Pessoais (PDAs) e telefones inteligentes interconectados por redes sem fios, entre outras, que possibilitam a comunicação de diversos profissionais em ambientes diferentes. Com o surgimento das TIMS, muitas organizações precisam readaptar sua estrutura tecnológica, seus processos de negócio, seus recursos humanos, suas formas de liderança e sua cultura organizacional para se adequar aos novos tipos de atividades que envolvem a mobilidade dos trabalhadores (BASOLE, 2008).

Diante da difusão das TIMS no mundo corporativo e sua aplicação a diversos processos de negócio, o que 
originou o conceito de mobilidade empresarial, diversos autores como: Katz (1997); Kristoffersen e Ljungberg (1998); Nah; Siau; Sheng (2005); Tarasewich; Nickerson; Warketing (2001); Lyytinen; Yoo (2002); Dekleva (2002); Kalakota; Robinson (2002); Sorensen (2008); Tamminen; Oulasvirta; Toiskallio; Kankainen (2003); Saccol; Reinhard (2006) e Scornavacca (2008) discutiram os seus efeitos para as organizações e os trabalhadores.

Segundo Nah, Siau e Sheng (2005), as aplicações móveis podem ser utilizadas para apoiar o $m$-business (negócios móveis), de forma a disponibilizar e melhorar tanto a mobilidade (usuários trabalhando a qualquer hora e em qualquer lugar); a flexibilidade (que permite aos usuários a coleta e o acesso a dados na fonte); e a divulgação dos produtos com maior suporte informacional, em diferentes locais e momentos.

$\mathrm{Na}$ indústria farmacêutica, a mobilidade já é uma realidade há mais de uma década. Taurion (2003) realizou uma pesquisa na área farmacêutica internacional destacando que essa indústria é precursora na adoção da mobilidade. Esse pioneirismo ocorreu devido ao grau de investimento em tecnologia na área da produção para adquirir e aperfeiçoar em larga escala as tarefas advindas da fabricação, maximizar o tempo, o capital e os equipamentos utilizados, bem como para obter racionalização do uso da matéria-prima, sua manipulação na produção e automação nas vendas.

Vivenciando essa situação histórica, a indústria farmacêutica brasileira, para superar a concorrência e manter-se no mercado, teve que alinhar estrategicamente seus recursos tecnológicos às habilidades e aptidões dos colaboradores e aos ajustes dos processos e da estrutura organizacional (VALLE; TOFFANI, 2007).

Nesse contexto de sobrevivência e turbulência do setor, o profissional de vendas tornou-se um dos colaboradores mais importantes. Segundo Clark, Rocco e Bush (2007, p. 68) o “[...] vendedor passou a desempenhar um papel extremamente importante na relação entre comercialização e a produtividade organizacional", porque é ele quem fica no Front Office, isto é, na linha de frente, passando uma imagem positiva e mantendo uma comunicação ativa entre o comprador e a empresa.

Nas últimas décadas, com a difusão das tecnologias para automação da força de vendas baseadas em TIMS, os profissionais da área comercial da indústria farmacêutica vêm alterando seu perfil. Antes, tinham a incumbência de conduzir os negócios com limitada acessibilidade, enquanto viajavam para mais perto do cliente (Front Office). Com a implantação das TIMS, esses profissionais também passaram a exercer funções de Back Office, que é a:

[...] incorporação e utilização de sistemas de gestão de negócios, sistemas legados e repositórios de dados operacionais como, por exemplo, a aplicação do CRM [Customer Relationship Management, ou ferramentas para gestão do relacionamento com clientes]. (VICENTE; MARTUCCI JÚNIOR, 2009, p. 24).

Com isso, o profissional de vendas passou a trabalhar com as informações em qualquer local, podendo gerar vantagem competitiva com seu uso.

Diante dessa breve contextualização, este estudo tem o intuito de contribuir para os avanços das discussões acerca do desenvolvimento das competências individuais do profissional da área comercial na indústria farmacêutica, a partir do uso intensivo de Tecnologias da Informação Móveis e Sem Fio (TIMS) no seu dia a dia de trabalho, ou seja, a partir da difusão da mobilidade empresarial.

O estudo enfoca a indústria farmacêutica goiana, mais especificamente, as organizações do Distrito Agroindustrial de Anápolis (DAIA). Essa escolha se deve ao crescimento desse polo e aos constantes investimentos que realiza na área tecnológica, como em aplicação de TIMS, e também em programas de qualificação profissional, os quais ajudaram o polo de Anápolis a se tornar o terceiro maior do país (CASTRO; BRITO, 2002). A pesquisa procurou explorar a seguinte questão: Quais são as decorrências do uso das Tecnologias da Informação Móveis e Sem Fio (TIMS) para as competências dos profissionais da área comercial na indústria farmacêutica no Estado de Goiás?

Devido à escassez de estudos científicos e trabalhos acadêmicos que abordem as decorrências do uso das TIMS para as competências individuais dos profissionais da área comercial na indústria farmacêutica no Brasil, tornam-se necessárias e interessantes pesquisas que considerem as peculiaridades desse contexto. Tais pesquisas poderão fornecer informações, com embasamento teórico, para os gestores e os profissionais dos departamentos de vendas e de recursos humanos, entre outros, sobre como proceder nas políticas e nas práticas de gestão de 
pessoas, ao implementar ou renovar as TIMS adotadas nos processos comerciais.

O artigo está assim estruturado: na primeira seção, será apresentada a literatura que embasou o estudo (Seção 1); a seguir, o método de pesquisa adotado (Seção 2), a análise dos dados coletados (Seção 3) e, por fim, as considerações finais do estudo, onde são indicadas outras questões para pesquisa futura.

\section{Fundamentação teórica}

Esta seção aborda os dois principais temas do estudo: (1.1) o uso de TIMS nas organizações (mobilidade empresarial) e o trabalho móvel; e (1.2) as competências dos profissionais da área comercial.

\subsection{Mobilidade empresarial e trabalho móvel}

As Tecnologias da Informação Móveis e Sem Fio (TIMS) podem ser conceituadas como ferramentas e aplicações móveis que envolvem aparelhos como laptops, PDAs, telefones inteligentes, que podem operar conectados ou não a uma rede (SACCOL; REINHARD, 2006). $\mathrm{O}$ uso das TIMS nas organizações gerou o conceito de mobilidade empresarial (SORENSEN et al. 2008), que envolve o uso de diferentes tipos de TIMS para apoiar processos de negócios, além de possibilitar novos canais de vendas (mobile commerce, ou comércio móvel).
Segundo Sorensen et al (2008, p. 260), ao se introduzir o uso de tecnologias móveis nas organizações, os profissionais responsáveis pela implantação terão seis diferentes desafios para buscar ganhos de eficiência organizacional, conforme demonstrado no Quadro 1. Os diferentes aspectos levantados pelos autores ampliaram o conhecimento teórico sobre as possíveis consequências das aplicações móveis nas organizações, como por exemplo, a interação e a comunicação ocorrendo em qualquer lugar e em qualquer hora, o que gera desafios para a liderança. É preciso compreender como a tecnologia é assimilada pelos profissionais e como a estratégia organizacional deve estar preparada para as mudanças a partir da possível melhoria na qualidade dos serviços.

O uso das TIMS, entre outras decorrências, passou nas últimas décadas, cada vez mais a apoiar o chamado trabalho móvel. Kristoffersen e Ljungberg (1998) descrevem três tipos de trabalho móvel que podem ser apoiados pelas TIMS: trabalhar em movimento, viajar e visitar. Trabalhar em movimento é uma atividade caracterizada por profissionais que se movem constantemente dentro do seu local de trabalho ou em torno dele. Viajar é uma atividade que ocorre ao se deslocar para qualquer local em um veículo, seja de carro, de trem, ou de avião; enquanto que visitar é o tempo gasto por uma pessoa ao trabalhar em outro local específico (KRISTOFFERSEN; LJUNGBERG, 1998).

Quadro 1 - Desafios da mobilidade empresarial

\begin{tabular}{|c|c|c|}
\hline Temas & Questões & Características \\
\hline Interação & Mediar ou Situar? & $\begin{array}{l}\text { A tecnologia móvel pode mediar a interação remota permitindo que a } \\
\text { comunicação ocorra em qualquer lugar e em qualquer hora. No entanto, } \\
\text { as tecnologias móveis também podem proporcionar a interação num } \\
\text { determinado lugar com o objetivo de fornecer informações específicas. }\end{array}$ \\
\hline Gerenciamento & Controle ou Discrição? & $\begin{array}{l}\text { A tecnologia móvel pode oferecer à gestão ferramentas que proporcionam } \\
\text { maior controle dos seus liderados, como também oferecer dados que podem } \\
\text { levar à descentralização na hora das decisões. }\end{array}$ \\
\hline Colaboração & Individual ou Coletivo? & $\begin{array}{l}\text { A tecnologia móvel pode oferecer tanto suporte individual para que as } \\
\text { atividades sejam realizadas, como também, oferecer acesso a informações } \\
\text { ou a ligações ocasionais com colegas e clientes. }\end{array}$ \\
\hline Tecnologia & Ubíquos ou Opacos? & A tecnologia móvel pode ser onipresente como também exigir atenção. \\
\hline Organização & Cultivar ou Transformar? & $\begin{array}{l}\text { A tecnologia móvel pode apoiar e melhorar as práticas já existentes nas } \\
\text { organizações, como também, transformar a maneira da tomada de decisões, } \\
\text { das inovações ou dos serviços prestados. }\end{array}$ \\
\hline Serviços & $\begin{array}{l}\text { Encontros ou } \\
\text { Relacionamentos? }\end{array}$ & $\begin{array}{l}\text { A tecnologia móvel pode ampliar a capacidade de ocorrer mais encontros e } \\
\text { também, fornecer suporte aos relacionamentos já existentes. }\end{array}$ \\
\hline
\end{tabular}

Fonte: Sorensen et al. (2008, p. 260). 
Em relação ao trabalho móvel, Gebauer e Shaw (2004) reforçam que os impactos do uso das tecnologias móveis dentro das organizações acontecem por causa da compactação dos processos de negócio, e isso resulta na redução do tempo ocioso e na possibilidade de distribuição das tarefas mais uniformemente em todo tempo e espaço. Essa compactação dos processos de negócio impacta operacionalmente no aumento da produtividade do empregado, permite que os trabalhadores se mantenham informados sobre qualquer acontecimento enquanto estão fora do escritório e ainda permite maior flexibilidade e capacidade da organização para lidar com situações de emergência. As TIMS oferecem uma grande flexibilidade na gestão da comunicação e na coordenação das práticas dos trabalhadores no dia a dia, além de servir como ferramentas para intermediar os interesses conflitantes, gerir a interação entre os membros e as suas práticas de aprendizagem, ajudar a reduzir custos de forma significativa na comunicação e na coordenação entre os membros da organização (KAKIHARA; SORENSEN, 2002).

De acordo com Rangone et al. (2007), as tecnologias móveis podem tanto otimizar os processos como ajudar a coordenar os recursos físicos e humanos e controlar negócios. Entretanto, a organização deve trabalhar a conscientização dos parceiros para uma cultura mais colaborativa e alinhar as políticas internas com o objetivo traçado, bem como integrar-se melhor às ideias do departamento de TI.

Em um estudo mais recente, Ziv (2008) relata que, a partir do surgimento das TIMS, os gestores tiveram que olhar para fora dos limites de suas corporações para acessar recursos inovadores que trouxessem melhoramento técnico dos produtos e infraestrutura móvel. E ainda reafirma que os impactos das tecnologias móveis nas organizações obrigaram os gestores a reavaliar os modelos de negócios existentes, contratar talentos adequados para trabalhar com a tecnologia e por fim, aperfeiçoar os produtos e serviços oferecidos.

Percebe-se que a tecnologia móvel trouxe benefícios e desafios tanto para as empresas quanto para os consumidores. Os benefícios e os desafios impactaram nas mudanças no plano individual do trabalhador, nas relações interorganizacionais, nos processos, na dinâmica de trabalho (TAMARU; HASUIKE, 2005), nas atividades, na coordenação, no compartilhamento de documentos e na troca de conhecimento (FROLICK; CHEN, 2004).
Mediante as transformações ocorridas pelo uso das TIMS, Jessup e Robey (2002) afirmam que, mesmo as equipes utilizando essas novas tecnologias, ainda não abandonaram as tecnologias mais antigas como o telefone ou mesmo o contato face a face para resolver problemas de comunicação. Os autores sugerem estudos minuciosos com relação ao comportamento individual e às equipes que trabalham com as velhas e as novas práticas.

As organizações precisam submeter suas políticas de gestão de pessoas a mudanças, a fim de atender à nova demanda de atividades que vai surgir com a implantação de tecnologias. Essa alteração pode ocorrer nas áreas de treinamento, de colocação e de recolocação dos profissionais para se executarem novas funções (MEISTER, 1999). Observa-se, nesse sentido, que é fundamental compreender o conceito de competências para identificar as decorrências do uso das TIMS para as funções dos profissionais da área comercial na indústria farmacêutica.

\subsection{Competências dos profissionais da área comer- cial}

Pode-se afirmar, de acordo com Boterf (2003), que as competências em nível individual (foco desta pesquisa) envolvem saberes, habilidades e atitudes aplicadas de forma integrada na ação profissional. Fleury e Fleury (2004) e Zarifian (2001) propõem que as competências devem agregar valor para a organização e para os indivíduos.

Conforme Zarifian (2001), existem mutações profundas do trabalho que vão desde o evento da inserção das máquinas até a organização que passou por transformações na divisão de trabalho, e que influenciaram tanto o trabalho como o trabalhador. Isso exigiu das empresas melhor planejamento na distribuição das atividades a serem executadas e maior competência do trabalhador para executar as atividades.

Segundo Clark, Rocco e Bush (2007), a profissão da área comercial parte da premissa da construção de relações de longo prazo com os clientes, adicionando, dessa forma, um valor benéfico tanto para o cliente como para a organização. Entretanto, com o surgimento de novas tecnologias, o profissional de vendas foi incorporando novas responsabilidades, como ajudar a manter a produtividade das vendas e, no caso da indústria farmacêutica, ajudar a promover os medicamentos.

Barros (1983, p. 380) comenta que, na promoção de medicamentos, a técnica de marketing desenvolvi- 
da e aplicada pela indústria farmacêutica no decorrer dos anos foi crucial, principalmente quando se trata da adoção de novos medicamentos; por isso, particularmente na América Latina, o papel do profissional da área comercial também pode ser de propagandista do produto. A comunicação entre os profissionais da área comercial com os médicos por meio da divulgação dos produtos e da entrega das amostras grátis é essencial para que os médicos receitem aos próprios pacientes os medicamentos recomendados (MANCHANDA; XIE; YOUN, 2005).

Não só os autores Manchanda, Xie e Youn (2005) afirmam a relevância do uso do marketing como meio de obter sucesso nas vendas, mas Leffler (1981), Lilien, Rao e Kalish (1981) e Swinyard e Ray (1977) também reafirmam a efetividade do contato físico entre o profissional da área comercial da indústria farmacêutica e o médico como meio de diminuir as dúvidas dos médicos com relação aos medicamentos.

De acordo com Boujena et al. (2009), o crescimento em investimento nas tecnologias móveis está cada vez mais ajudando as organizações a conquistarem clientes, melhorando as habilidades dos profissionais da área comercial. Os autores ainda ressalvam que, diante de alguns depoimentos dos clientes, o uso das tecnologias móveis pode incidir em cinco funções da interação vendedorconsumidor. São elas:

$\mathbf{1}^{\mathrm{a}}$ - $\mathrm{O}$ aumento na produtividade - significa a capacidade do vendedor em ter mais informações sobre o cliente e, a partir disso, compreender as necessidades dos seus clientes e oferecer mais alternativas para a negociação, o que, por sua vez, induz a menos erros por parte do vendedor na hora de interpretar dados e análises enviadas pela organização.

$2^{\mathrm{a}}$ - $\mathrm{O}$ processamento de informação - consiste na capacidade do sistema de automação de vendas em fornecer informações o mais rápido possível. Portanto, o profissional da área comercial deve ter habilidade de analisar os dados e superar seus concorrentes, oferecendo produtos e serviços mais apropriados para o cliente.

$3^{\text {a }}$ - A eficácia da comunicação - são as tecnologias que ajudam o profissional da área comercial a obter as devidas informações no intuito de repassá-las aos clientes de forma clara e rápida. $4^{\mathrm{a}}$ - A competência percebida - é a capacidade de o cliente perceber o conhecimento e a competência do profissional da área comercial nas diversas áreas relacionadas aos produtos e aos serviços, sua capacidade em compreender as necessidades atuais e visualizar o cenário do mercado no intuito de melhorar a compreensão das futuras necessidades dos clientes.

\section{$5^{\mathbf{a}}$ - A qualidade da relação com os clientes - con-} siste na capacidade da automação de vendas ajudar a construir um valor intangível entre o vendedor e o comprador, como a confiança e a satisfação.

Seguindo esse raciocínio, Geiger e Turley (2006, p. 831) delinearam cinco capacidades importantes que os profissionais de vendas na indústria farmacêutica devem possuir. São elas:

1) Saber ouvir: saber ouvir os clientes é essencial para manter o bom relacionamento.

2) Especialidade: a especialização tem-se tornado primordial com a inserção de novas tecnologias na indústria farmacêutica e aos poucos se tornou também uma ferramenta necessária para construir relações de longo prazo e de confiança entre os profissionais de vendas com a empresa e com os clientes.

3) Adaptabilidade/Receptividade: o profissional de vendas deve ser adaptável a qualquer ambiente e ser receptivo a quaisquer circunstâncias que envolvam a negociação.

4) Comunicação: capacidade do profissional em transmitir informações necessárias e verdadeiras para o cliente e para a equipe de trabalho como um todo.

5) Confidencialidade: capacidade do profissional de vendas de se relacionar ao longo do tempo com cliente e com a empresa, mantendo sigilo na troca de informação.

Destaca-se que, com o decorrer do tempo, os vendedores passaram a desempenhar um papel extremamente importante na relação entre a comercialização e a produtividade organizacional, pois são eles que mantêm uma comunicação ativa com os compradores, podendo influenciar na fabricação de produtos ou na prestação dos serviços da empresa. Assim, conclui-se que as empresas têm o intuito de otimizar as competências de cada profissional, como a capacidade de relacionamento, a comunicação com os clientes e até mesmo o repasse das informações corretas. Para isso, elas estão investindo cada vez mais em tecnologias como as TIMS. 


\section{Método de pesquisa}

Este estudo abordou um fenômeno contemporâneo dentro de seu contexto real, aplicando o método de estudos de casos múltiplos (YIN, 2001). Foram pesquisadas duas indústrias farmacêuticas localizadas no DAIA (Distrito Agroindustrial de Anápolis) em Goiás. Elas serão aqui denominadas empresa "Beta Max" e "Alfa", buscando preservar suas identidades.

Foram utilizadas como técnicas de coleta de dados a entrevista semiestruturada e a análise dos sites das empresas pesquisadas, bem como alguns documentos internos. As entrevistas foram realizadas nas duas orga- nizações com os diretores da área de Tecnologia da Informação (TI), Comercial, Recursos Humanos (RH) e com os profissionais da área comercial, totalizando 07 entrevistados na empresa Beta Max e 05 na empresa Alfa, conforme demonstrado no Quadro 2. Na empresa Beta Max, todos os profissionais envolvidos com a área comercial foram entrevistados. Porém, não foi entrevistado o diretor do Departamento de Recursos Humanos. Já na empresa Alfa, todos os gestores dos departamentos de TI, Comercial e RH foram entrevistados, além de dois representantes de vendas que atendem o estado de Goiás. As entrevistas foram realizadas no período de maio a agosto de 2010.

Quadro 2 - Relação das entrevistas realizadas nas empresas pesquisadas

\begin{tabular}{|c|c|c|c|c|c|}
\hline Caso 1-Beta Max & $\begin{array}{c}\text { Local da } \\
\text { Entrevista }\end{array}$ & Entrevistados & $\begin{array}{c}\text { Caso 2 - } \\
\text { Alfa }\end{array}$ & $\begin{array}{c}\text { Local da } \\
\text { Entrevista }\end{array}$ & Entrevista-dos \\
\hline $\begin{array}{c}\text { Diretor da área } \\
\text { comercial }\end{array}$ & Na organização & 1 & $\begin{array}{c}\text { Coordenadora da } \\
\text { área comercial }\end{array}$ & Na organização & 1 \\
\hline $\begin{array}{c}\text { Diretor da área } \\
\text { da TI }\end{array}$ & Na organização & 1 & $\begin{array}{c}\text { Diretor da área } \\
\text { da TI }\end{array}$ & Na organização & 1 \\
\hline $\begin{array}{c}\text { Diretor da área } \\
\text { de RH }\end{array}$ & Na organização & - & $\begin{array}{c}\text { Coordenadora da } \\
\text { área de RH }\end{array}$ & Na organização & 1 \\
\hline $\begin{array}{c}\text { Profissio-nais da } \\
\text { área comercial }\end{array}$ & Cafeterias & 5 & $\begin{array}{c}\text { Profissionais da } \\
\text { área comercial }\end{array}$ & Cafeterias & 2 \\
\hline \multicolumn{2}{|c|}{ Total de Entrevistados } & $\mathbf{7}$ & Total de Entrevistados & $\mathbf{5}$ \\
\hline
\end{tabular}

Fonte: do autor.

Para efetuar as entrevistas com maior acuracidade, elaborou-se para cada gestor (RH, TI e Comercial) e para os profissionais da área comercial, roteiros com perguntas específicas. Os blocos de perguntas se dividiram em tópicos sobre: (1) TIMS adotadas e processo de adoção; (2) Perfil dos profissionais da área comercial, bem como processos de gestão de RH sobre esses profissionais e (3) Decorrências do uso das TIMS, especialmente considerando as competências dos profissionais de vendas. As entrevistas tiveram um tempo de duração compreendido entre 30 minutos e 01 hora cada uma e foram gravadas para posterior transcrição e análise dos dados. Para análise dos dados foram utilizados os seis passos descritos por Creswell (2007): (1º) Organização e preparação dos dados para análise; $\left(2^{\circ}\right)$ Leitura de todos os dados (reflexão sobre seu sentido global); ( $\left.3^{\circ}\right)$ Análise detalhada com um processo de codificação, organização do material em grupos temáticos; $\left(4^{\circ}\right)$ Codificação, para gerar uma descrição dos temas de análise; (5º) Organização da descrição dos temas na narrativa qualitativa; e $\left(6^{\circ}\right)$ Interpretação dos resultados.

Na seção seguinte, os dados serão analisados para conduzir às conclusões do estudo.

\section{Análise dos dados}

A análise dos dados se inicia com uma breve apresentação das duas empresas estudadas, a Beta Max e a Alfa. A seguir, os dados são analisados de forma sintética, ressaltando especialmente os resultados comuns encontrados em ambos os casos pesquisados.

Para melhor visualização dos dados de pesquisa, foram elaborados quatro quadros com a síntese dos dados (ver Quadros 3, 4, 5 e 6) sobre os resultados encontrados em três principais elementos pesquisados: 
(1) Histórico de adoção das TIMS e os tipos de tecnologias adotadas em cada empresa;

(2) Perfil dos profissionais da área comercial e práticas de gestão de RH sobre esses profissionais nas empresas pesquisadas;

(3) Decorrências da adoção das TIMS, de maneira geral e, principalmente, para as competências dos profissionais pesquisados;

Cabe comentar que a análise do processo de adoção das TIMS, do perfil e das práticas de gestão de RH dos profissionais de vendas serve como subsídio para compreender as decorrências do uso de TIMS para a competência dos profissionais pesquisados (foco principal da pesquisa).

\subsection{Apresentação das empresas pesquisadas}

A empresa Beta Max atua no setor farmacêutico há mais de 40 anos e hoje possui em torno de 1.300 colaboradores. Os seus produtos são específicos para os hospitais, governo e farmácias, pois são produtos que só podem ser manipulados por pessoas capacitadas.

A empresa atende basicamente a clientes corporativos como hospitais, governo e farmácias, com portfólio amplo: alimentação Enteral e Parenteral, ampolas de vidro e de plástico, especialidades hospitalares em sistema fechado, medicamentos genéricos, soluções especiais, soluções parenterais básicas, soluções parenterais em bolsa de trilaminado soluflex, soluções parenterais especiais e soluções parenterais Istarbag.

Sempre atenta às mudanças e com o lema "evolução permanente" a empresa Beta Max almejou e conquistou certificados da ISO 9001 e 14001. Ao longo dos anos, com diversos investimentos direcionados, conseguiu obter uma estabilidade financeira, mesmo havendo nesse ramo de atividade um alto índice de competitividade.

A empresa Alfa atua no ramo de medicamentos genéricos e similares, especificamente no segmento da indústria farmacêutica há mais de 60 anos. Hoje a empresa tem em torno de 1.800 colaboradores. Os seus produtos são vendidos para as farmácias e distribuidoras e não são necessárias pessoas qualificadas para manipular os medicamentos genéricos ou similares, tornando-se produtos

\subsubsection{Processo de adoção de TIMS nas empresas pes- quisadas}

No Quadro 3 são apresentados os resultados comuns sobre o histórico de adoção das TIMS e as tecnologias adotadas nas Empresas Beta Max e Alfa. Algumas particularidades de cada empresa são também descritas a seguir.

Como o Quadro 3 demonstra, as empresas implantaram o uso principalmente de PDAs e laptops, e de alguns telefones celulares inteligentes para apoiar o trabalho dos seus representantes comerciais em campo, permitindo-lhes o acesso a módulos de vendas dos seus sistemas ERP. É importante mencionar que as empresas já utilizavam tecnologias móveis há mais de uma década, porém, em 2009, ambas atualizaram o uso de tal tecnologia com a introdução de novos recursos.

Quadro 3: Histórico de adoção das TIMS e tecnologias adotadas nas empresas

\section{Histórico de adoção das TIMS e das tecnologias nas empresas Beta Max e Alfa}

As empresas já tinham investido nas TIMS e, em 2009, ambas buscaram agilizar o processo de vendas. Com isso, fizeram um upgrade na tecnologia.

Ambas investiram nos PDAs, smartphones e laptops, para uso conjunto com o telefone celular corporativo.

Nas empresas estudadas, a maioria dos profissionais trabalha com laptop e celular; alguns, com telefones inteligentes (smartphones).

Ambas não solicitaram a ajuda da área de $\mathrm{RH}$ para implantação das TIMS.

Ambas tiveram desafios em fazer com que os representantes trabalhassem com a nova tecnologia.

As empresas treinaram e capacitaram os profissionais da área comercial a trabalhar com as TIMS de forma pontual (treinamentos de curta duração). Não houve capacitação sobre mudanças no perfil ou processos de trabalho

Ambas as empresas trabalham com sistema ERP, com módulos específicos da área comercial, sendo acessados pelos dispositivos móveis.

As funcionalidades do sistema que são utilizadas pelos profissionais são semelhantes: envio de pedido, e-mail, confirmação do pedido e situação do cliente na empresa (crédito, pagamentos, etc.).

Fonte: Dados da pesquisa

A história de adoção das TIMS na empresa Beta Max havia iniciado em 1990 e, naquela época, foram oferecidos aos profissionais da área comercial os aparelhos Palm e laptop e, mais tarde, telefones celulares com tecnologia 2G. Em 2009, A Beta Max também passou a ofe- 
recer 05 tipos de aparelhos móveis para os representantes: PDAs, Smartphones (incluindo o uso de BlackBerry $\left.{ }^{\bullet}\right)$, Pockets e Netbooks com acesso à tecnologia 3G. Essas eram as opções de aparelhos, sendo que o representante poderia escolher o que considerasse melhor para trabalhar. Mesmo a empresa ofertando diferentes alternativas, os aparelhos mais usados são os celulares e os laptops; somente um dos 05 entrevistados utiliza um PDA.

Na empresa Alfa os profissionais de vendas já utilizavam Palmtops desde 2003. Em 2009, resolveu-se atualizar a tecnologia, e a empresa repassou aos seus representantes de vendas um "auxílio informática". Esse auxílio refere-se a um valor depositado na conta do representante, até ele quitar a dívida da compra do aparelho móvel, para que possa comprar o aparelho que deseja. Os dois profissionais que atendem ao mercado goiano preferiram adquirir laptops e utilizá-los com o celular para executar suas tarefas rotineiras.

As empresas tiveram que transpor desafios durante a adoção das TIMS, como, por exemplo, fazer com que os representantes com mais tempo de empresa se adaptassem e trabalhassem com a nova tecnologia. A empresa Alfa, em particular, teve dificuldade para localizar uma organização que fornecesse um sistema de informação com todas as peculiaridades que desejava e que atendesse todo o território nacional.

Os treinamentos e a capacitação foram realizados pelos gestores de TI e da área comercial de uma forma rápida e com foco na tecnologia. Durante esse processo, somente as funcionalidades do sistema foram mostradas, $\mathrm{e}$ os gestores não enfatizaram a importância dos processos ou dos novos papéis que os representantes iriam executar.

Verificou-se que ocorreram mudanças no trabalho com as inserções de novas tecnologias. Diante disso, a literatura aponta que as empresas devem melhorar o planejamento da distribuição das atividades a serem executadas e treinar com profundidade para qualificar o trabalhador para executar as atividades rotineiras com o apoio da tecnologia, e não somente capacitar para o uso das ferramentas tecnológicas em si, o que corrobora a afirmação de Zarafian (2001).

A empresa Beta Max enfrentou ainda o desafio de qualificar os funcionários dos departamentos de TI e do Comercial para auxiliarem os representantes comerciais e também para convencer novos profissionais contra- tados sobre a importância do uso das TIMS. Durante o processo da adoção das tecnologias móveis, em ambas as empresas, percebeu-se que os gestores treinaram e capacitaram os representantes para utilizar as TIMS mesmo sem o envolvimento da área de RH nesse processo. Entretanto, verificou-se que a participação do RH na empresa Alfa é bem mais ativa do que na empresa Beta Max. Um exemplo disso são os investimentos em sistemas de informações para gerar melhores informações para a área de $\mathrm{RH}$, como ferramentas de BI (Business Intelligence).

Nesse contexto, ressalta-se que as empresas, em geral, devem considerar o papel estratégico do $\mathrm{RH}$, que também é responsável por ajudar a desenvolver tanto o indivíduo como a organização, por meio das políticas de manutenção de RH. Segundo Zarafian (2001), o RH pode ser um apoiador ativo na implantação das tecnologias, já que elas afetam diretamente o perfil e as competências dos profissionais. Por isso, na seção seguinte, examina-se o perfil dos profissionais de vendas das empresas pesquisadas e como funciona (de maneira geral) seu processo de gestão de pessoas.

\subsubsection{Perfil dos profissionais de vendas e gestão de pessoas nas empresas pesquisadas}

No Quadro 04, visualizam-se pontos comuns a respeito do perfil dos profissionais da área comercial nas empresas Beta Max e Alfa, bem como aspectos relativos à gestão de pessoas desses profissionais em específico, nas duas empresas pesquisadas.

Percebe-se que os perfis dos profissionais de vendas são semelhantes entre as empresas, inclusive na exigência do conhecimento sobre tecnologia. Todos são representantes autônomos, não tendo vínculo empregatício com as empresas, o que torna mais complexa a gestão desses profissionais.

De acordo com um representante comercial da empresa Beta Max: "Meu papel hoje é visitar cliente, vender produtos da empresa, trabalhar com editais, com o processo de licitação. Eu faço todo o processo de licitação, eu capto edital, monto edital e a proposta".

$\mathrm{Na}$ empresa Alfa, as atividades das vendas enfocam três mercados: vendas a distribuidoras, a grandes redes de farmácias e vendas ao distribuidor hospitalar. Portanto, a principal função dos representantes é visitar ou se manter sempre em contato com a carteira de clientes corporativos. 
Quadro 04 - Perfil dos profissionais e gestão de pessoas na área comercial

\begin{tabular}{|l|}
\hline $\begin{array}{c}\text { Perfil dos profissionais e gestão de pessoas na área } \\
\text { comercial nas empresas pesquisadas }\end{array}$ \\
\hline $\begin{array}{l}\text { Os profissionais da área de vendas não fazem visitação } \\
\text { médica, somente visitação e venda corporativa; executam } \\
\text { suas tarefas } 100 \% \text { fora da sede da empresa, não têm } \\
\text { vínculo empregatício e se mantêm constantemente em } \\
\text { contato com os clientes. }\end{array}$ \\
\hline $\begin{array}{l}\text { Os perfis esperados dos profissionais em ambas as } \\
\text { empresas, são: ser graduado, ter boa comunicação, saber } \\
\text { negociar e ter conhecimentos em informática. }\end{array}$ \\
\hline $\begin{array}{l}\text { A Gestão de Pessoas, em ambas as empresas, tem o perfil, } \\
\text { a função e as habilidades dos profissionais de vendas } \\
\text { detalhados no manual de cargos e funções, mas nenhuma } \\
\text { delas trabalha a gestão por competências. }\end{array}$ \\
\hline $\begin{array}{l}\text { O foco do treinamento, em ambas as empresas, está nas } \\
\text { vendas/produtos. }\end{array}$ \\
\hline A avaliação é centrada no alcance das metas de vendas. \\
\hline
\end{tabular}

Fonte: Dados da pesquisa

Com relação aos pontos de semelhança na Gestão de Pessoas, ambas as empresas têm o perfil, a função e as habilidades dos profissionais de vendas detalhadas no manual de cargos e funções. Esse controle facilita os processos para admitir, demitir ou realocar os funcionários que não se encaixarem no perfil desejado pela empresa.

Quanto aos processos de avaliação e de treinamento, notaram-se algumas diferenças entre as empresas. A Beta Max avalia seus profissionais com foco nas vendas, mas não fornece feedback, deixando os representantes sem saber se estão conseguindo realizar o trabalho conforme as normas e os objetivos da empresa. Já a empresa Alfa se destaca na gestão dos profissionais de vendas, visto que trabalha com a premissa de valorização e de movimentação com a aplicação da política de cargos e de salários e promoções aos seus representantes comerciais, considerando a avaliação deles e dando-lhes feedbacks a respeito.

Outro ponto semelhante é que o Departamento de RH, em ambas as empresas, não aplica a gestão por competências. Entretanto, a empresa Alfa já manifesta a vontade de trabalhar com essa abordagem.

\subsubsection{Decorrências gerais da adoção de TIMS nas em- presas pesquisadas}

No Quadro 5, apresentam-se, de maneira geral, os aspectos comuns sobre as decorrências da adoção das TIMS nas empresas Alfa e Beta Max. As decorrências para as competências dos profissionais serão identifica-
Quadro 5 - Decorrências (gerais) da adoção das TIMS nas empresas Beta Max e Alfa.

\section{Decorrências da adoção das TIMS (de maneira geral) nas empresas pesquisadas}

As principais vantagens apontadas pelas empresas com adoção das TIMS, são: agilidade no pedido e na entrega do produto; acesso a informações sobre as transações de negócio em tempo real, em qualquer local.

Maior facilidade no processo de supervisão (maior acesso a dados em campo).

Facilidade na obtenção de dados sobre vendas (produtos, clientes, informações financeiras) e agilidade na comunicação.

Redução de erros (e seus custos) no processo de vendas.

Os gestores de ambas as empresas não veem nenhuma desvantagem na adoção das TIMS.

TIMS reduz a privacidade dos usuários.

Fonte: Dados da pesquisa

$\mathrm{Na}$ etapa da coleta de dados, verificou-se que a maioria dos representantes comerciais já atuava nessa função antes do surgimento das tecnologias móveis. Com a adoção das TIMS, as funções vender e entregar o produto ficaram mais ágeis. De acordo com o diretor comercial da empresa Beta Max:

Com a adoção das TIMS os custos diminuíram. Diminuiu quando eliminou o tempo gasto refazendo trabalho realizado de forma errada, produtos sendo fabricado sem ter necessidade por que interpretaram de forma errada a letra do vendedor ou produto sendo entregue sem o cliente ter pedido. Com relação à velocidade podemos afirmar que hoje o pedido de compra é online, nisso o vendedor pesquisa em tempo real e tem o estoque do produto e quando pode ser entregue, e a informação sobre a situação financeira do cliente é em tempo real.

$\mathrm{O}$ ato de comunicar e de informar as empresas sobre o processo da venda ou resolver qualquer problema passou a ser executado em um curto espaço de tempo. Segundo um representante comercial da empresa Alfa:

Eu realizo minhas atividades boa parte através do e-mail, acessando parte do programa existente da empresa. A gente passa os pedidos, a gente tem como ver estoque, como ver carteira do cliente, essas informações básicas de vendas a gente tem elas atualizadas a cada cinco minutos.

Nas entrevistas, foi detectado que o uso das TIMS estimulou as vendas e o vendedor passou a ter informações necessárias e relevantes para desempenhar seu papel de maneira mais eficiente do que antes. Wright e Donaldson (2007) comentam que a automação das vendas dei- 
xou as organizações mais flexíveis em relação ao ato de gerenciar e supervisionar.

Com as informações certas, hoje os representantes comerciais gerenciam melhor o trabalho do dia a dia, sendo capazes de resolver diversos tipos de problemas relacionados às vendas, usando as funcionalidades oferecidas pelos aparelhos móveis, corroborando estudos de Hunter e Perrault (2006). Traçando um paralelo da literatura com os dados obtidos nas empresas pesquisadas, os profissionais de vendas conseguem se mover e, ao mesmo tempo, consultar informações e solucionar problemas utilizando as funcionalidades das TIMS, como: agendas eletrônicas integradas ao banco de dados do cliente, acesso aos dados sobre a história dos clientes, informação sobre os produtos, o estoque e o correio eletrônico, entre outros. A automação melhorou o acesso à informação, à rapidez na comunicação interna e externa e à criação de relatórios confiáveis. Além disso, fez com que os representantes incorporassem na função diária a cobrança, função esta que antes era feita por um departamento interno da empresa (BackOffice).

Cabe comentar que, quanto às decorrências da adoção das TIMS, não foi relatada a existência de desvantagens por parte dos gestores entrevistados em todas as áreas e em ambas as empresas. No entanto, para dois representantes da empresa Alfa existe uma desvantagem: a falta de privacidade. O celular tem que ficar 24 horas ligado, caso a organização necessite dos serviços dos representantes. Conforme relato de um deles:

A vantagem é a rapidez de retorno, a gente sempre dá uma melhor atenção para o cliente. O ruim é por se tratar de um telefone corporativo e está sempre ligado, eles vão sempre saber o que você está fazendo, onde você está, você não tem privacidade, se você tem que fazer qualquer coisa além, eles ficam sabendo por que tem os celulares, então de certa forma te tira um pouco a privacidade.
Torna-se interessante destacar a falta de percepção (ou, pelo menos, reconhecimento) de aspectos negativos da adoção das TIMS por parte dos gestores. Autores como Saccol e Reinhard (2006) e Sorensen et al. (2008) descrevem desvantagens que também ocorrem pelo uso das tecnologias móveis, como, por exemplo, a falta de privacidade ou a sobrecarga de informação. Acredita-se que os gestores e a maioria dos representantes entrevistados não apontaram nenhum aspecto negativo porque o uso das TIMS tornou-se "natural" no dia a dia, mas seria importante considerar as decorrências para a sua qualidade de vida, por exemplo.

\subsection{Decorrências do uso de TIMS para as competên- cias dos profissionais de vendas}

É importante ressaltar que, uma vez que ambas as empresas pesquisadas não trabalham a gestão por competências, os profissionais entrevistados descreveram mudanças nas competências dos profissionais de vendas conforme o seu entendimento próprio. Portanto, verificou-se que apontaram mudanças no perfil, nas habilidades e nos conhecimentos dos profissionais pesquisados. O Quadro 6 demonstra as decorrências da adoção das TIMS para as competências dos profissionais da área comercial nas empresas pesquisadas, conforme a representação dos entrevistados.

Nas empresas estudadas, percebeu-se que o uso intensivo das TIMS nos processos de trabalho dos profissionais da área comercial afetou suas atribuições, suas responsabilidades e suas habilidades e, por decorrência, suas competências.

O uso das TIMS potencializou as habilidades de saber ouvir o cliente e a transmissão das informações, já que estas podem ser acessadas em tempo real e as comunicações com os clientes são intensificadas com o uso das tecnologias móveis. 
Quadro 6 - Decorrências da adoção das TIMS para as competências dos profissionais

\section{Decorrências da adoção das TIMS para as competências dos profissionais de vendas}

O uso das TIMS potencializou as habilidades de saber ouvir o cliente e a transmissão das informações, a especialização, o ser adaptável a qualquer ambiente e o ser receptivo a diferentes circunstâncias que envolvam a negociação.

Houve aumento da realização de atividades de BackOffice pelos profissionais da área comercial, bem como, da autonomia em gerenciar as informações sobre clientes e os produtos. Com isso, são demandadas competências de gestão dos profissionais sobre os diversos processos que realizam em seu dia a dia de trabalho.

Ampliou-se o nível de complexidade das atribuições e das responsabilidades dos representantes sem alterar o cargo.

Houve exigência de maior agilidade e menor tempo de resposta às demandas pelos profissionais e maior cobrança por resultados.

O perfil "gostar e saber trabalhar com tecnologia" passou a ser exigido pelas empresas em relação ao perfil dos profissionais de vendas.

Fonte: Dados da pesquisa

A especialização e a adaptação a qualquer ambiente e as circunstâncias que envolvam a negociação também se intensificaram com o uso das TIMS, que disponibiliza aos profissionais da área comercial mais informações para subsidiar o processo de negociação. É possível, por exemplo, saber exatamente quais produtos estão em estoque, o tempo de entrega e mesmo as condições financeiras do cliente, as informações fundamentais para o processo de negociação e o fechamento de vendas.

Desse modo, verificou-se que o profissional passou a ser mais exigido quanto à sua competência de gestão dos diversos processos que realiza no dia a dia, pois, junto com o acesso a mais informações, ele também passou a ter que executar e gerenciar atividades que antes eram de incumbência do pessoal de retaguarda (BackOffice). A adoção das TIMS ampliou o nível de complexidade das atribuições e das responsabilidades do profissional da área comercial, mesmo sem uma alteração do cargo.

Ao mesmo tempo, o uso das TIMS aumentou a demanda de resposta dos profissionais, pois o acesso à informação em tempo real, de qualquer local, faz com que a cobrança por resultados desses profissionais seja cada vez mais imediata, conforme relata a Diretora de TI da empresa Alfa:

A área comercial trabalha muito com objetivos e metas, então está tudo muito bem estruturado na área comercial. [os representantes] sabem que produtos têm que vender por mês e quantidade. Eles têm vários níveis de metas, são premiados de acordo com essas metas, já tem tudo isso até o final do ano, eles sabem exatamente o que tem que ser atingido e são remunerados com o cumprimento dessas metas. E através do sistema eles sabem que tem de visitar uma quantidade certa de clientes por mês.

Outra mudança foi a obrigatoriedade do profissional gostar e dominar o uso das tecnologias móveis que precisa utilizar em seu dia a dia de trabalho. O diretor da área comercial da empresa Beta Max foi enfático ao afirmar que:

Hoje você falar de um profissional [de vendas] que não tem conhecimento de informática, está fora do mercado. Então, se é um profissional que não conhece informática, ele não vai trabalhar não só aqui na organização, ele não vai trabalhar em outra empresa. Juntamente com esse perfil, nós vamos analisar os aspectos da experiência, saber abordar e negociar com o cliente, ter atitude e ser dedicado para ver se ele é competente ou não na sua função.

Portanto, percebeu-se que a adoção das TIMS colaborou para incrementar o processo de vendas, influenciando o perfil e as competências dos profissionais da área comercial. É preciso considerar que os vendedores não são mais "tiradores de pedido", mas, sim, profissionais que precisam ser hábeis em negociar, em entender o mercado, em saber comunicar e que precisam ser valorizados por terem informações relevantes sobre o mercado e os clientes. Em concordância com Fleury e Fleury (2004), o trabalho não é mais o conjunto de tarefas associadas descritivamente ao cargo, mas se torna prolongamento direto da competência que o indivíduo mobiliza em face de uma situação profissional cada vez mais mutável e complexa. Na próxima seção, serão apresentadas as considerações finais do estudo.

\section{Considerações Finais}

O objetivo principal deste estudo foi identificar as decorrências do uso das TIMS para as competências de profissionais da área comercial na indústria farmacêutica no estado de Goiás. A seguir, serão apresentadas as principais considerações da pesquisa, bem como as contri- 
buições acadêmicas e práticas e, por fim, indicações para trabalhos futuros.

Inicialmente, destaca-se que as TIMS trouxeram vantagens, benefícios e desafios para as duas empresas pesquisadas. Referências como as de Katz (1997), Gebauer e Shaw (2004), Kakihara e Sorensen (2002), Tamaru e Hasuike (2005), Frolick e Chen (2004) corroboram os resultados a seguir:

- As comunicações e interações tornaram-se mais rápidas assim como o fluxo dos processos, especialmente o processo comercial.

- As empresas obtiveram melhor acesso ao cliente e maior controle dos profissionais.

- Houve redução de erros no processo de vendas em campo e, consequentemente, redução dos custos decorrentes desses erros (ex: pedidos indevidos).

- A adoção das TIMS agilizou o processo das vendas, fornecendo meios para que o profissional (representante comercial) tenha mais autonomia para resolver problemas.

Nesse sentido, é importante salientar que todos os gestores entrevistados, em ambas as empresas pesquisadas, não identificaram nenhum tipo de desvantagem no uso das TIMS, sendo que somente dois representantes comerciais entrevistados apontaram a perda de privacidade como uma decorrência indesejada da tecnologia. Essas evidências indicam que talvez falte um olhar mais crítico em relação à adoção da mobilidade empresarial, que tem decorrências tanto positivas quanto negativas (SACCOL; REINHARD, 2006), as quais precisam ser discutidas e trabalhadas pelos setores de TI da área de negócios afetada e também com a participação ativa da área de gestão de pessoas da organização.

Verificou-se que o uso das TIMS afetou o perfil, as atribuições, as responsabilidades e as competências dos profissionais de vendas. O resultado é um perfil profissional mais complexo que precisa ser mais bem capacitado para, entre outras atividades, gerenciar o fluxo de informações e os processos que executa em seu dia a dia, que são tanto de linha de frente (FrontOffice) quanto alguns processos de retaguarda (BackOffice), sendo estes últimos incorporados às suas funções devido ao acesso a informações antes indisponíveis em campo (ex: dados financeiros dos clientes, informações sobre cobrança).

Diante desse contexto, para que a adoção das TIMS tenha êxito, as empresas devem cuidar do tempo de implantação do sistema, da promoção de uma capacitação que seja suficiente para que o profissional entenda não só como usar as novas TIMS, mas também as decorrências das mudanças em seu trabalho, as novas habilidades e as exigências de competências comportamentais e técnicas para desempenhar o seu papel com o apoio da tecnologia.

Este estudo também aponta a falta de integração existente entre os processos de adoção de TIMS e os processos de gestão de pessoas, pois, conforme os casos demonstraram, não houve participação da área de RH no processo de adoção e capacitação para o uso da tecnologia nas duas empresas pesquisadas. Também não houve análise alguma das decorrências para o perfil do profissional e para as necessidades de capacitação derivadas dessas mudanças. Cada vez mais se percebe a necessidade da atuação estratégica da gestão de pessoas (DUTRA, 2002). Acredita-se que, nessa atuação, também estejam incluídas as atribuições de um olhar mais atento e crítico sobre o processo de adoção de novas tecnologias para apoio ao trabalho e às suas decorrências para os profissionais.

Com relação à contribuição acadêmica deste estudo, considerando que há poucos trabalhos que abordam a questão das TIMS e os impactos nas competências dos profissionais da área comercial, de forma geral, no estado de Goiás ou na indústria farmacêutica, especificamente, é oferecida uma referência que verifica alguns dos reflexos da utilização das TIMS para as empresas que as adotam. Além disso, a pesquisa possibilitou a análise de aspectos do processo da adoção das TIMS nas empresas pesquisadas, os desafios, as vantagens e as facilidades encontradas pelos gestores das empresas, as principais habilidades e os conhecimentos demandados dos profissionais pesquisados.

A discussão sobre a forma como o uso das TIMS afeta as competências dos profissionais pode ser pertinente a outras organizações que queiram adotar as tecnologias móveis em processos da área comercial. No entanto, devido ao caráter desta pesquisa ser qualitativo e a quantidade de pessoas entrevistadas ser baixa, os resultados não podem ser generalizados estatisticamente. 
Eles podem, porém, gerar insights pertinentes a outras empresas semelhantes.

Para trabalhos futuros, sugere-se que haja pesquisas sobre o uso das TIMS por outros profissionais da área comercial em diferentes indústrias e em diferentes locais. Também sugere-se que seja investigado em profundidade o quanto o profissional da área comercial, sem vínculo empregatício, consegue exercer um papel estratégico nas empresas, conforme estudo do autor Rocha (2003). Além disso, é necessário estudar o quanto a incorporação dos serviços do BackOffice influencia a mudança do perfil do profissional da área comercial.

Também caberiam estudos correlacionados à importância da área de Gestão de Pessoas no processo de adoção das TIMS e de outras TICs e estudos em outras empresas farmacêuticas que adotem TIMS e que realizem visitação médica. Por fim, propõe-se que, futuramente, estudos semelhantes utilizem uma abordagem quantitativa para que se possa obter generalização estatística de resultados encontrados.

\section{Referências}

BASOLE, R. C. Enterprise mobility: Researching a new paradigm. Information Knowledge Systems Management, Amsterdam, v. 7, n.1-2, p. 1-7, 2008.

BARROS, J. A. C. Estratégias mercadológicas da indústria farmacêutica e o consumo de medicamentos. Revista Saúde Pública, São Paulo, v. 17, p. 377-386, 1983.

BORTEF, G. Desenvolvendo a competência dos profissionais. 3. ed. Porto Alegre: Artmed, 2003.

BOUJENA, O.; JOHNSTON, W. J; MERUNKA, D. R. The Benefits of Sales Force Automation: A Customer's Perspective. Journal of Personal Selling \& Sales Management, v. 29, n. 2, p. 137-150, spring, 2009.

CASTRO, S.; BRITO, L.. Sistemas produtivos locais no Estado de Goiás: o caso da indústria farmacêutica do eixo Goiânia-Anápolis. Disponível em: <www.seplan.go.gov. br/sepin/pub/conj/conj5/07>. Acesso em: 01 dez. 2008.

CLARK, P.; ROCCO, R. A; BUSH, A. J. Sales Force Automation Systems and Sales Force Productivity: Critical Issues and Research Agenda. Journal of Relationship Marketing, EUA, v. 6, n. 2, 2007.

CRESWELL, J. W. Projeto de pesquisa: métodos qualitativo, quantitativo e misto. Porto Alegre: Artmed, 2007.
DUTRA, J. S. Gestão de pessoas: modelo, processos, tendências e perspectivas. São Paulo: Atlas, 2002.

FLEURY, M.; FLEURY, A. Estratégias empresariais e formação de competências: um quebra cabeça caleidoscópio da indústria brasileira. 3. ed. São Paulo: Atlas, 2004.

FROLICK, M. N.; CHEN, L. Assessing M-Commerce Opportunities. Information Systems Management, Pittsburgh, p.53-61, Spring, 2004.

GEBAUER, J.; SHAW, M. J. Success Factors and Impacts of Mobile Business Applications: Results from a Mobile e-Procurement Study. International Journal of Electronic Commerce. EUA, v. 8, n. 3, p. 19 - 41. Spring, 2004.

GEIGER, S.; TURLEY, D. The Perceived Impact of Information Technology on Salespeople's Relational Competencies. Journal of Marketing Management, n. 22, p.827-851, 2006.

HUNTER, G. K.; PERREAUlT, W. D. Jr. Sales Technology Orientation, Information Effectiveness, and Sales Performance. Journal of Personal Selling \& Sales Management, v. 26, n. 2, p. 95-113. Spring, 2006.

KALAKOTA, R; ROBINSON, M. M-business: tecnologia móvel e estratégia de negócios. Porto Alegre: Bookman, 2002.

KAKIHARA, M.; SORENSEN, C. Mobility: an extended perspective. In: HAWAII INTERNATIONAL CONFERENCE ON SYSTEM SCIENCES, 35., 2002, Hawai. Proceedings... Hawai, 2002.

KATZ, J. E. Social and organizational consequences of wireless communications: a selective analysis of residental and business sectors in the United States. Telematics and Informatics. v. 14, n. 3, p 233-256, 1997.

KRISTOFFERSEN, S.; LJUNGBERG, F. Your mobile computer is a stationary computer. Norwegian Computing Center, Postboks 114 Blindern, n. 0314 OSLO, Norway, 1998.

LEFFLER, K. B. Persuasion or information? The economics of prescription drug advertising. Journal of Law and Economics, v. 24, n. 1, p. 45-74, abr. 1981.

LILIEN, G. L.; RAO, A. G.; KALISH, S. Bayesian estimation and control of detailing effort in a repeat purchase diffusion environment. Management Science, v. 27, n. 5, p. 493-506, maio, 1981.

LYYTINEN, K.; YOO, Y. Research Commentary: The Next Wave of Nomadic Computing. Information Systems Research, v. 13, n. 4, p. 377-388, Dec. 2002. 
MANCHANDA, P.; XIE, Y.; YOUN, N. The role of targeting communication and contagion in product. Marketing Science, v. 27, n. 6, p. 961-976, Nov./Dec. 2008.

MEISTER, J. C. Educação corporativa: a gestão do capital intelectual através das Universidades Corporativas. São Paulo: Pearson Markron Books, 1999.

NAH, F.; SIAU, K.; HONG, S. The value of mobile applications: a utility company study. Communications of the acm, v. 48, n. 2, p.85-90, Feb. 2005.

RANGONE, A. et al. Mobile e Wireless Business Applications in the Italian Utility Market: an empirical study and a decision model. In: INTERNATIONAL CONFERENCE ON MOBILE BUSINESS, 2007, Toronto. Annals... Toronto: ICMB, 2007.

ROCHA, R. R.V. Elaboração e aplicação de um modelo de gestão do conhecimento adaptado para o departamento comercial de uma indústria farmacêutica. 2003. 130f. Dissertação (Mestrado Profissionalizante) - Universidade Federal do Rio Grande do Sul, Rio Grande do Sul, 2003.

SACCOL, A.; REINHARD, N. Tecnologias de informação móveis, sem fio e ubíquas: definições, estado-da-arte e oportunidades de pesquisa. Revista de Administração Contemporânea, v. 11, n. 4, 2006.

SORENSEN, C. et al. Exploring enterprise mobility: Lessons from the Field. Information Knowledge Systems Management, v.7, n.1, p.243-271, 2008.

SWINYARD, W. R.; RAY, M. L. Advertising-Selling Interactions: an attribution theory experiment. Journal of Marketing Research, v. 14, p. 509-516, Nov. 1977.

TAMARU, E., HASUIKE, K., TOZAKI, M. Cellular Phone as a Collaboration Tool that Empowers and Changes the Way of Mobile Work: Focus on Three Fields of Work. ECSCW 2005. In: EUROPEAN CONFERENCE ON COMPUTER-SUPPORTED COOPERATIVE WORK: proceedings, 9., 2005, Paris. Annals... Netherlands: Springer, 2005. p. 247-266.
TAURION, C. Cenários das aplicações móveis para os próximos anos. [S.1.]: Mobile Corporate; Fórum. IBM, 2003.

VALLE, F M; TOFFANI, F. A aplicação do endomarketing na transformação do clima organizacional da indústria farmacêutica, 2007. Disponível em <http:// www.webartigos.com/articles/1719/1/a-aplicacaodo-endomarketing-na-transformacao-do-climaorganizacional-da-industria-farmaceutica/pagina 1. html>. Acesso em: 15 mar. 2009.

VICENTE, S. A.; MARTUCCI JUNIOR, M. Aplicação dos Padrões ODP e TMN no Gerenciamento de Sistemas Corporativos Distribuídos: sistemas de CRM. Revista de Engenharia de Computação e Sistemas Digitaisn, 1, p. 2131, 2003.

ZARIFIAN, P. Objetivo: competência. São Paulo: Atlas, 2001.

ZIV, N. Exploring Convergence and Innovation on the Mobile Plataform: mobile social media services as a case in point. New York: Polytechnic University, 2008.

WRIGHT, G.; DONALDSON, B. Sales information systems in the UK financial services industry: an analysis of sophistication of use and perceived barriers to adoption. International Journal of Information Management, v. 4, p. 251-263, 2004.

YIN, R. K. Estudo de caso: planejamento e método. Porto Alegre: Bookman, 2001. 


\section{Para publicar na revista Universitas Gestão e TI, entre no endereço eletrônico www.publicacoesacademicas.uniceub.br.}

Observe as normas de publicação, facilitando e agilizando o trabalho de edição. 